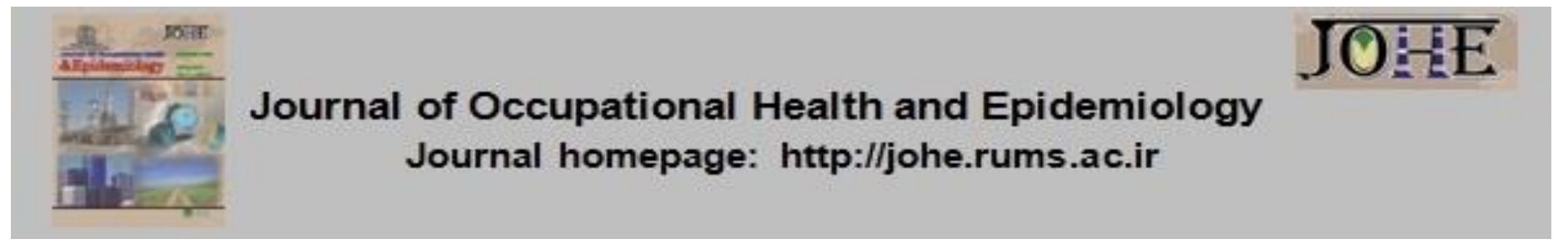

\title{
Lower Serum Levels of Antibodies against Tetanus Toxin in Patients with Hypothyroidism
}

Mohammad-Taghi Rezayati ${ }^{1}$, Ahmad-Reza Sayadi², Ziba Shaabani ${ }^{3}$, Shokoofeh Moghaddam $^{4}$, Azam Bagherizdaeh ${ }^{4}$, Fereshteh Iranmanesh ${ }^{5}$, Vahid Ehsani ${ }^{6}$, Fahimeh Mohammadizadeh ${ }^{4}$, Shima Bazaz $^{4}$, Abdollah Jafarzadeh ${ }^{*}$

1. BSc in Laboratory Sciences, Dept. of Immunology, Medical School, Rafsanjan University of Medical Sciences, Rafsanjan, Iran.

2. Assistant Prof, Social Determinants of Health Research Center, Rafsanjan University of Medical Sciences, Rafsanjan, Iran.

3. Assistant Prof, Immunology of Infectious Diseases Research Center, Research Institute of Basic Medical Sciences, Rafsanjan University of Medical Sciences, Rafsanjan, Iran.

4. BSc in Laboratory Sciences, Pathobiological Laboratory, Medical School, Rafsanjan University of Medical Sciences, Rafsanjan, Iran.

5. BSc in Biology, Dept. of Pathology, Medical School, Rafsanjan University of Medical Sciences, Rafsanjan, Iran.

6. MSc in Physiology, Dept. of Physiology, Medical School, Rafsanjan University of Medical Sciences, Rafsanjan, Iran.

7. Professor, Dept. of Immunology, Medical School, Rafsanjan University of Medical Sciences, Rafsanjan, Iran \& Dept. of Immunology, Medical School, Kerman University of Medical Sciences, Kerman, Iran.

Citation: Rezayati MT, Sayadi AR, Shaabani Z, Moghaddam S, Bagherizdaeh A,
Iranmanesh F, Ehsani V, Mohammadizadeh F, Bazaz S, Jafarzadeh A. Lower Serum Levels
of Antibodies against Tetanus Toxin in Patients with Hypothyroidism. J Occu Health
Epidemiol $2021 ; 10(3): 134-9$.

\section{Article Info}

* Corresponding author: Abdollah Jafarzadeh,

E-mail:

Jafarzadeh14@yahoo.com

\section{Article history}

Received: Jun 2021

Accepted: Oct 2021

10.52547/johe.10.3.134

Print ISSN: 2251-8096 Online ISSN: 2252-0902

Peer review under responsibility of Journal of Occupational Health and Epidemiology

\section{Abstract}

Background: A fundamental duty of the immune system is to defend against infectious agents. Significant abnormalities were reported in immune parameters of hypothyroid and hyperthyroid patients. In this study, we aim to assess various quantities of antibodies against the tetanus toxin (anti-TT) in hypothyroid and hyperthyroid patients.

Materials and Methods: Anti-TT levels were measured in serum samples from 50 hypothyroid patients, 50 hyperthyroid patients, and 50 euthyroid individuals, using the ELISA method. Besides, the minimum protective quantity of anti-TT was considered 0.1 $\mathrm{IU} / \mathrm{mL}$.

Results: Seroprotective rates against tetanus were 100,80 , and $96.0 \%$ in euthyroid, hypothyroid, and hyperthyroid groups with the means of $3.52 \pm 0.31,1.62 \pm 0.21$, and $4.07 \pm 0.32 \mathrm{IU} / \mathrm{ml}$, respectively. Accordingly, hypothyroid patients exhibited lower anti-TT levels and seroprotective rates than the euthyroid group $(P<0.001$ and $P<0.004$, respectively). Besides, in the hypothyroid group, anti-TT quantities and seroprotective rates were lower than those in hyperthyroid individuals $(P<0.001$ and $P<0.03$, respectively).

Conclusions: The findings demonstrated lower immunity and higher susceptibility to tetanus in patients with hypothyroidism. However, more studies are needed to be conducted in this field to provide more data to be considered in health programs.

Keywords: Human, Hypothyroidism, Hyperthyroidism, Antibody, Tetanus Toxin

\section{Introduction}

Contamination of wounds with spores of grampositive anaerobic bacillus Clostridium (C) tetani and the release of a bacterium-derived neurotoxin lead to tetanus [1]. Although an efficient antitetanus vaccine is available, tetanus has remained a crucial public health concern. Around one million deaths occur annually due to this disease worldwide [1, 2]. Tetanus is infrequent in healthy 
individuals receiving complete vaccine doses; however, insufficient and incomplete immunization against tetanus as well as poor care of the wounds are related to tetanus, especially in ages over 65 [3]. The Advisory Committee on Immunization Practices (ACIP) advised a series of immunizations, including five doses of the Diphtheria-Tetanus-Pertussis (DTP) vaccine for infants and young children with single immunization using TT, the reduced DiphtheriaPertussis (TdP) vaccine for adolescents and adults, as well as a booster vaccine dose of the $\mathrm{Td}$ vaccine every 10 years or when wound management is needed [1, 4, 5]. In Iran, vaccination with a local DTP vaccine (manufactured by the Razi Institute) began in 1950 [6].

Hypothyroidism is frequent in regions with adequate levels of iodine so that the rate of hypothyroidism is about $1-2 \%$, which increases to about $7 \%$ in individuals aged 85-89 [7]. Besides, the rate of overt hyperthyroidism is about $0.2-1.3 \%$ in regions with adequate iodine. The rate of overt hypothyroidism is about $0.2-5.3 \%$ in Europe and $0.3-3.7 \%$ in the USA [7]. Annual frequencies of subclinical and overt hypothyroidism were reported to be about 7.62 and 2.0 per thousand, respectively, in Tehran, a region with adequate iodine [8].

A strong bidirectional interplay exists between the immune system and the neuroendocrine system. Thyroid-related hormones can influence the functions of various types of leukocytes, including lymphocytes, natural killer cells, monocytes, and macrophages [9]. Major abnormalities were reported in immune parameters of hypothyroid and hyperthyroid patients [10, 11]. Patients with hyperthyroidism commonly display an imbalance in immune responses, including unusual antibody production [9]. Hypothyroid patients suffer impairments in their immune system and vulnerability to infections [9]. Vaccination provides significant protection against infectious diseases. However, vaccination-mediated immunity has not been evaluated adequately in patients suffering from thyroid disorders. This investigation was conducted to measure the serum quantities of antibodies against the tetanus toxin (anti-TT) in hypothyroid or hyperthyroid patients.

\section{Materials and Methods}

Two groups of patients were enrolled in this descriptive cross-sectional study, who included 50 hypothyroid patients (aged $38.8 \pm 16.15$ ) and 50 hyperthyroid patients (aged $37.2 \pm 16.17$ ). They had been referred to the Pathobiological
Laboratory affiliated to the Rafsanjan University of Medical Sciences (Rafsanjan, Iran). Hypothyroid and hyperthyroid disorders were diagnosed according to clinical and paraclinical evidence.

Apart from clinical observations, such as weight loss, tachycardia, arrhythmia, increased appetite, nervousness, anxiety, fatigue, muscle weakness, and skin thinning, some other indices, including decreased serum quantities of $\mathrm{TSH}$, elevated serum amounts of T3, and T4 hormones (T4 > 160 $\mathrm{nmol} / \mathrm{L}, \mathrm{T} 3>3.6 \mathrm{nmol} / \mathrm{L}, \mathrm{TSH}<0.35 \mathrm{mIU} / \mathrm{L})$ were used in diagnosing hyperthyroidism. Development of symptoms (fatigue, sensitivity to cold, weight gain, constipation, muscle weakness, joint swelling, thinning hair, irregular menstrual periods, depression, and enlarged thyroid), increased serum quantities of TSH accompanied with reduced serum amounts of T3 and T4 (T4 < 60 $\mathrm{nmol} / \mathrm{L}, \mathrm{T} 3<1.6 \mathrm{nmol} / \mathrm{L}, \mathrm{TSH}>3.5 \mathrm{mlU} / \mathrm{L})$ were regarded as the criteria for hypothyroidism diagnosis [10]. Interpretation of T4 levels with the corresponding TSH was considered a highaccuracy index for the diagnosis of hypothyroidism or hyperthyroidism [12].

The euthyroid group that included gender-matched healthy individuals (aged $37.4 \pm 14.50$ ) with normal tests for thyroid hormones were enrolled as the control (T4: $60-160 \mathrm{nmol} / \mathrm{L}$, T3: $1.8-3.6 \mathrm{nmol} / \mathrm{L}$, TSH: $0.35-3.5 \mathrm{mIU} / \mathrm{L})$. Taking medications for hypothyroidism or hyperthyroidism, smoking cigarettes, having a surgery history, as well as suffering from illnesses, such as infectious diseases, malignant diseases, allergies, and doubtful immunological disorders were considered as the exclusion criteria. The participants were not treated with immunomodulating drugs and had normal cell blood counts (CBC), lipids profiles, as well as liver and renal-related function tests.

The Ethics Committee of Rafsanjan University of Medical Sciences confirmed the procedure of this research and written informed consent was obtained from all participants. Besides, a peripheral blood specimen (2-4 $\mathrm{mL}$ ) was obtained from each participant, and their serums were isolated and kept at $-20{ }^{\circ} \mathrm{C}$.

As already mentioned, universal immunization with the DTP vaccine started in 1950 in Iran [6]. As the participants were born after that date, they routinely received the DTP vaccine. Besides, primary immunization had been achieved using three injections at the ages of 2, 4, and 6 months, followed by three booster injections at the ages of 18-24 months, 4-6 years, and 18-24 years [6].

Serum quantities of the specific anti-TTA were detected using ELISA commercial kits (IBLHamburg $\mathrm{GmbH}$, Hamburg, Germany) as explained previously [13]. In brief, $100 \mu \mathrm{L}$ of 
standard and serum specimens was pipetted into the specified ELISA plate wells covered with a tetanus toxin. Next, the plates were incubated at room temperature (RT) for 60 minutes to bind the specific antibodies in the samples to the coated antigen in the wells. Besides, the wells were washed using a washing buffer (by a $300 \mu \mathrm{L} /$ well 4 times) to remove the unbounded antibodies. Next, $100 \mu \mathrm{L}$ conjugate (the enzyme-labeled antibody against human $\lg G$ ) was added to the wells. After the incubation time for 30 minutes at RT, the wells were washed again as described. Next, $100 \mu \mathrm{L}$ of a substrate solution (Tetramethylbenzidine) was added to the wells, and the plate was incubated at RT for 20 minutes in the dark. The enzyme activity was terminated by adding sulfuric acid (50 $\mu \mathrm{L} /$ well). Besides, the optical density of the wells was measured at $450 \mathrm{~nm}$ using an ELISA reader system. The density of the developed color was equal to the concentration of the anti-TT.

According to the manufacturer's instructions, the anti-TT concentrations expressed as $\mathrm{IU} / \mathrm{mL}$ and the levels of $\geq 0.1 \mathrm{JU} / \mathrm{mL}$ were regarded as protective concentrations of the antibodies. ELISA sensitivity was $0.004 \mathrm{IU} / \mathrm{ml}$.

The student's t-test and the Chi-square test were used for the analysis of the results using SPSS software (V21.0, Chicago, IL, USA), and a p-value less than 0.05 was considered significant.

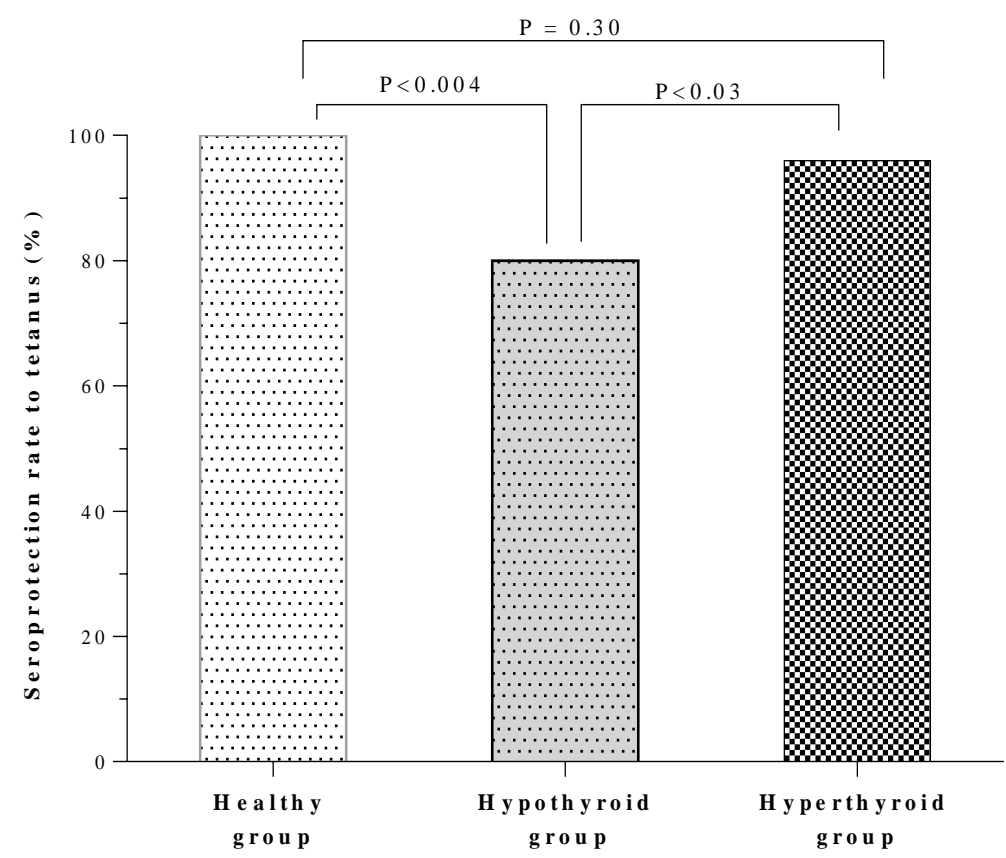

Fig. 1. Seroprotective rates against tetanus in healthy subjects and patients with hypothyroidism and hyperthyroidism; the seroprotective rate against tetanus was lower in the hypothyroid patients than in the control and hyperthyroid groups $(P<0.004$ and $P<0.03$, respectively $)$

\section{Results}

Seroprotective rates in hypothyroid and hyperthyroid patients: Seroprotective rates against tetanus were 100, 80 , and $96 \%$ in the healthy, hypothyroid, and hyperthyroid groups. The hypothyroid patients exhibited a lower anti-TT seroprotective rate against tetanus than the healthy and hyperthyroid patients $(P<0.004$ and $P$
$<0.03$, respectively). Besides, no remarkable difference was found between the healthy and hyperthyroid groups in the seroprotective rate (Fig. 1). In the healthy group, seroprotective rates against tetanus were expressed similarly in the men and women. In the hypothyroid and hyperthyroid groups, all men were seroprotective, while seroprotective rates were found to be 73 and $94 . \%$ in the women, respectively (Table 1 ).

Table 1. Serum anti-TT levels and seroprotective rates in healthy, hypothyroid, and hyperthyroid groups

\begin{tabular}{cccccc}
\hline Groups & Number & $\begin{array}{c}\text { Serum anti-TT levels } \\
\text { (IU/ml) }\end{array}$ & Skewness & Kurtosis & $\begin{array}{c}\text { Seroprotective } \\
\text { rate [No (\%)] }\end{array}$ \\
\hline Healthy control & 50 & $3.52 \pm 0.31$ & $0.66 \pm 0.33$ & $-0.11 \pm 0.66$ & $50(100.0 \%)$ \\
\hline Hypothyroid & 50 & $1.62 \pm 0.21$ & $1.45 \pm 0.33$ & $2.20 \pm 0.66$ & $40(80.0 \%)$ \\
\hline Hyperthyroid & 50 & $4.07 \pm 0.32$ & $0.51 \pm 0.33$ & $-0.05 \pm 0.66$ & $48(96.0 \%)$ \\
\hline
\end{tabular}

Symbol • indicates that anti-TT levels were expressed as the standard error of the mean (SEM). 


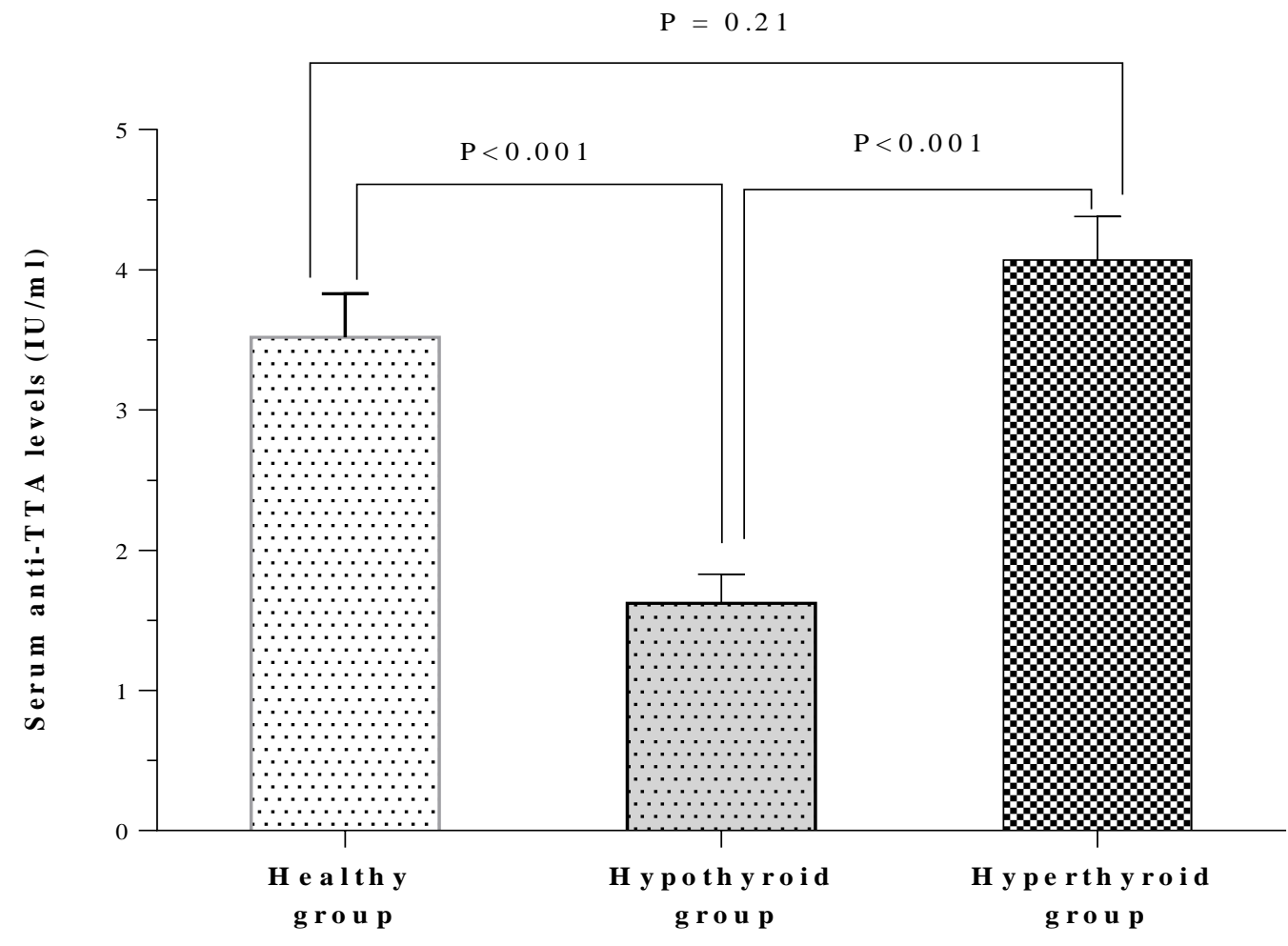

Fig. 2. Serum anti-TT levels in the healthy subjects and patients with hypothyroidism and hyperthyroidism; In the hypothyroid patients, serum anti-TT levels were lower than those in the control and hyperthyroid groups $(P<0.001)$

Anti-TT quantities in the hypothyroid and hyperthyroid patients: The means of anti-TT titers were $3.52 \pm 0.31,1.62 \pm 0.21$, and $4.07 \pm$ $0.32 \mathrm{IU} / \mathrm{ml}$, in the healthy, hypothyroid, and hyperthyroid groups, respectively (Table 1). Besides, the anti-TT levels were significantly lower in the hypothyroid patients than in the healthy and hyperthyroid groups $(P<0.001$ and $P<0.001$, respectively). However, the difference in the anti-
TT levels between the healthy and hyperthyroid groups was not significant (Fig. 2). In addition, no significant difference was detected between the men and the women in the serum quantities of anti-TT in the healthy individuals and in the thyroid patients. Nevertheless, the hyperthyroid men expressed higher levels of anti-TT than the women (Table 2).

Table 2. Serum anti-TT levels and seroprotective rates in healthy, hypothyroid, and hyperthyroid groups based on their gender

\begin{tabular}{|c|c|c|c|c|c|}
\hline Groups & Gender & Number & $\begin{array}{c}\text { Serum anti-TT levels } \\
(\mathrm{IU} / \mathrm{ml})^{\bullet}\end{array}$ & $\begin{array}{l}\text { Seroprotective } \\
\text { rates [No (\%)] }\end{array}$ & P-value \\
\hline \multirow{3}{*}{$\begin{array}{c}\text { Healthy } \\
\text { control }\end{array}$} & Men & 12 & $3.56 \pm 0.72$ & $12(100.0 \%)$ & \multirow{3}{*}{$\begin{array}{l}*=0.93 \\
* *=1.0\end{array}$} \\
\hline & Women & 38 & $3.50 \pm 0.34$ & $38(100.0 \%)$ & \\
\hline & Total & 50 & $3.52 \pm 0.31$ & $50(100.0 \%)$ & \\
\hline \multirow{3}{*}{ Hypothyroid } & Men & 13 & $1.45 \pm 0.22$ & $13(100.0 \%)$ & \multirow{3}{*}{$\begin{array}{l}{ }^{*} 0.66 \\
\text { NC }\end{array}$} \\
\hline & Women & 37 & $1.67 \pm 0.28$ & $27(73.0 \%)$ & \\
\hline & Total & 50 & $1.62 \pm 0.21$ & $40(80.0 \%)$ & \\
\hline \multirow{3}{*}{ Hyperthyroid } & Men & 11 & $5.30 \pm 0.85$ & $11(100.0 \%)$ & \multirow{3}{*}{$\begin{array}{l}{ }^{*} 0.10 \\
\text { NC }\end{array}$} \\
\hline & Women & 39 & $3.72 \pm 0.31$ & $37(94.0 \%)$ & \\
\hline & Total & 50 & $4.07 \pm 0.32$ & $48(96.0 \%)$ & \\
\hline
\end{tabular}

Symbol • indicates that anti-TT levels were expressed as the standard error of the mean (SEM). Besides, symbols * and ${ }_{* *}^{*}$ represent the comparison of serum anti-TT levels and protective rates, respectively. NC: not calculated as nonseroprotective in one group, being zero;

Based on the duration of the thyroid disease, each group of the hypothyroid or hyperthyroid patients was divided into two subgroups. In the hypothyroid patients with the disease duration $>5$ years, the seroprotective rate and the mean of the anti-TTA titer were lower than those in the patients with the disease duration $<5$ years, yet the difference was not significant (Table 3). However, no remarkable difference was found between the hyperthyroid patients with the disease period $>5$ years and those with the disease period $<5$ years in the seroprotective ratio and the mean of the anti-TTA titer (Table 3). 
Table 3. Serum quantities of the anti-tetanus toxin antibody in hypothyroid and hyperthyroid patients based on the disease duration

\begin{tabular}{|c|c|c|c|c|c|}
\hline Groups & $\begin{array}{c}\text { Disease duration } \\
\text { (year) }\end{array}$ & Number & $\begin{array}{c}\text { Serum anti-TT } \\
\text { levels } \\
\text { (IU/ml)• }\end{array}$ & $\begin{array}{c}\text { Protective rate } \\
\text { N (\%) }\end{array}$ & P-values \\
\hline \multirow{3}{*}{ Hypothyroid } & $<5$ & 24 & $1.71 \pm 0.32$ & $20(83.3 \%)$ & \multirow{3}{*}{$\begin{array}{l}{ }^{*}=0.67 \\
{ }^{* *}=0.57\end{array}$} \\
\hline & $>5$ & 26 & $1.53 \pm 0.29$ & $20(76.9 \%)$ & \\
\hline & Total & 50 & $1.62 \pm 0.21$ & $40(80.0 \%)$ & \\
\hline \multirow{3}{*}{ Hyperthyroid } & $<5$ & 23 & $4.19 \pm 0.47$ & $22(95.7 \%)$ & \multirow{3}{*}{$\begin{aligned} * & =0.72 \\
* * & =0.90\end{aligned}$} \\
\hline & $>5$ & 27 & $3.96 \pm 0.44$ & $26(96.3 \%)$ & \\
\hline & Total & 50 & $4.07+0.32$ & $48(96.0 \%)$ & \\
\hline
\end{tabular}

Symbol • indicates that the anti-TT levels were expressed as the standard error of the mean (SEM). Symbols * and ** represent the comparison of serum anti-TT levels and the protection rate, respectively.

\section{Discussion}

The data presented here indicate that the seroprotective rate and the anti-TT quantities were lower in the hypothyroid patients than in the healthy subjects. Therefore, the hypothyroid patients could have greater vulnerability to tetanus. Lower anti-TT quantities in the hypothyroid subjects could be attributed to some immune irregularities in these individuals. The production of the specific antibodies and the persistence of the immunological memory are complex processes that need coordination between immune cells, especially helper T (Th) cells, B cells, and antigenpresenting cells (APCs), such as dendritic cells and macrophages [14]. The existence of the receptor for thyroid-related hormones was documented on various kinds of leukocytes, such as macrophages, as well as $\mathrm{T}$, and $\mathrm{B}$ lymphocytes [9]. Therefore, it is logical that immune functions are impaired in hypothyroid individuals. It has been reported that the $B$ cell maturation is impaired in mice with the deficient thyroid hormone, yet the administration of T3 and T4 fully recovered this deficiency [15]. In addition, hypothyroid mice displayed a lower number of $B$ cells in their bone marrow than normal ones [15].

Vaccination is the most efficient strategy for providing immunity against infectious diseases mediated via immunologic memory induction [16]. The low anti-TT quantities in the hypothyroid patients could be partly due to immunological memory defects that probably made these patients susceptible to infectious diseases.

The present study showed that the anti-TT levels were higher in the hyperthyroid individuals than in the hypothyroid patients. Besides, a higher number of peripheral blood lymphocytes and an enhanced lymphocyte proliferation response were observed in the hyperthyroid animals. Moreover, higher serum IgG and IgA concentrations were observed in the hyperthyroid women than in the healthy women [10]. Although the seroprotective rate was lower in the hyperthyroid patients than in the healthy subjects, the anti-TT quantities did not seem to be reduced in these patients.

Our results showed that in both hypothyroid and hyperthyroid groups, seroprotective rates were greater in the men than in the women. Similar results were reported in other investigations [1719]. The elevated levels of anti-TT in the men could have been due to higher exposure to Clostridium tetani, leading to higher protective rates. In fact, this could be attributed to greater accident rates in the men. Men with a history of dirty ulcers or prevalent soil contamination generated higher anti-TT quantities [16]. Moreover, a group of men might have been vaccinated against tetanus during their military service. More investigations need to be carried out to explain reasons for the greater seroprotective rate against tetanus in men than in women.

\section{Conclusion}

In the present study, lower anti-TT levels were detected in the hypothyroid patients, indicating that hypothyroidism could negatively affect anti-TT levels and immunity against tetanus. The patients' gender could influence the seroprotective rates against tetanus. However, the immunity against tetanus could not be affected in the hyperthyroid subjects. More studies need to be conducted in this field to provide more data to be considered in health programs.

\section{Acknowledgement}

This research was supported by a grant [PN91026] from the Rafsanjan University of Medical Sciences, Rafsanjan, Iran, which is highly appreciated.

Conflict of interest: None declared.

\section{References}

1. Ataro P, Mushatt D, Ahsan S. Tetanus: a review. South Med J 2011; 104(8):613-7. 
2. Uket HO, Ekanem EE, Okpara HC, Ekrikpo UE. Comparative tetanus antibody response of Nigerian children to diphtheria-pertussis-tetanus and pentavalent vaccines. Niger Postgrad Med J 2018; 25(3):137-42.

3. Reed DB, Westneat SC. Exposure risks and tetanus immunization status in farmers ages 50 and over. South Med J 2009; 102(3):251-5.

4. Liang JL, Tiwari T, Moro P, Messonnier NE, Reingold A, Sawyer M, et al. Prevention of Pertussis, Tetanus, and Diphtheria with Vaccines in the United States: Recommendations of the Advisory Committee on Immunization Practices (ACIP). MMWR Recomm Rep 2018; 67(2):1-44.

5. Choi JH, Choo EJ, Huh A, Choi SM, Eom JS, Lee JS, et al. Immunogenicity and safety of diphtheria-tetanus vaccine in adults. $\mathrm{J}$ Korean Med Sci 2010; 25(12):1727-32.

6. Zarei S, Jeddi-Tehrani M, Akhondi MM, Zeraati $H$, Kheirkhah $T$, Ghazanfari $M$, et al. Immunogenicity of a triple diphtheria-tetanuswhole cell pertussis vaccine in Iranian preschool children. Iran J Immunol 2007; 4(2):101-9.

7. Taylor PN, Albrecht D, Scholz A, GutierrezBuey G, Lazarus JH, Dayan CM, et al. Global epidemiology of hyperthyroidism and hypothyroidism. Nat Rev Endocrinol 2018; 14(5):301-16.

8. Amouzegar A, Ghaemmaghami Z, Beigy $M$, Gharibzadeh S, Mehran L, Tohidi $M$, et al. Natural Course of Euthyroidism and Clues for Early Diagnosis of Thyroid Dysfunction: Tehran Thyroid Study. Thyroid 2017; 27(5):616-25.

9. Jara EL, Munoz-Durango N, Llanos C, Fardella C, Gonzalez PA, Bueno SM, et al. Modulating the function of the immune system by thyroid hormones and thyrotropin. Immunol Lett 2017; 184:76-83.

10. Jafarzadeh A, Poorgholami M, Izadi N, Nemati $M$, Rezayati M. Immunological and hematological changes in patients with hyperthyroidism or hypothyroidism. Clin Invest Med 2010; 33(5):E271-9.

11. Safdari V, Alijani E, Nemati $M$, Jafarzadeh $A$. Imbalances in $T$ Cell-Related Transcription Factors among Patients with Hashimoto's Thyroiditis. Sultan Qaboos Univ Med J 2017; 17(2):e174-e80.

12. Koulouri O, Gurnell M. How to interpret thyroid function tests. Clin Med (Lond) 2013; 13(3):2826.

13. Jafarzadeh A, Shabani Z, Hassanabadi $M$, Rezayati MT, Nemati M, Sayadi AR, et al. Lower immunity to tetanus in cigarette smoker subjects. J Occu Health Epidemiol 2012; 1(3):124-31.

14. Stebegg $M$, Kumar SD, Silva-Cayetano A, Fonseca VR, Linterman MA, Graca L. Regulation of the Germinal Center Response. Front Immunol 2018; 9:2469.

15. Dorshkind K, Horseman ND. The roles of prolactin, growth hormone, insulin-like growth factor-I, and thyroid hormones in lymphocyte development and function: insights from genetic models of hormone and hormone receptor deficiency. Endocr Rev 2000; 21(3):292-312.

16. Castellino F, Galli G, Del Giudice G, Rappuoli R. Generating memory with vaccination. Eur J Immunol 2009; 39(8):2100-5.

17. Wu CJ, Ko HC, Lee HC, Tsai WC, Li MG, Pao $Y Z$, et al. Decline of tetanus antitoxin level with age in taiwan. J Formos Med Assoc 2009; 108(5):395-401.

18. Alagappan K, Rennie W, Kwiatkowski T, Falck J, Silverstone F, Silverman R. Seroprevalence of tetanus antibodies among adults older than 65 years. Ann Emerg Med 1996; 28(1):18-21.

19. Nemati M, Zarrin M, Mir-Abdollah SA, Rezayati MT, Mirzaee V, Bagheri A, et al. Lower serum level of anti-tetanus toxin antibodies in patients with type 2 diabetes mellitus. Acta Med Indones 2014; 46(1):44-50. 